\title{
Editorial
}

\section{The many challenges of childhood blindness}

There are an estimated 45 million blind people in the world of whom only $3 \%$ are children. ${ }^{1}$ This dramatic difference in numbers of blind adults compared with children accounts in part for the relatively minor importance that has been attributed to the problem surrounding childhood blindness. Certainly, the well organised advocacy groups for the elderly in many developed countries are not matched by comparable ones for children. The result of this can be seen in the difference in resources made available for health services and research for adult blindness versus childhood blindness. One hopes that, now that the World Health Organization (WHO) and International Agency for Prevention of Blindness have developed a global initiative to eliminate avoidable blindness and have included childhood blindness as one of its five key areas, this will change. ${ }^{2}$ In this issue of the $B F O$ ( $\mathrm{p} 1149$ ) Kocur and co-workers report on the causes of severe visual impairment (visual acuity in the better eye less than 6/60) and blindness (visual acuity in the better eye less than 3/60) in the Czech Republic. This is an excellent study and the authors raise issues that go well beyond the borders of the Czech Republic. We wish to highlight only two of these issues.

First, and foremost, is the issue that the authors emphasise themselves-the continuing havoc resulting from retinopathy of prematurity (ROP). In this study ROP was the leading cause of blindness- $41.9 \%$ had ROP. Although this figure appears to be staggering at first, similar studies in Bulgaria and Cuba have reported incident rates of $25.9 \%$ and $38 / 6 \%$ respectively. ${ }^{3}$ The ever changing epidemiology of ROP is difficult to summarise precisely. The simplistic view that ROP is becoming less of a problem in the more developed nations while being a major problem in emerging nations, who are just now beginning to establish intensive care neonatal units, is misleading. Isolated reports have suggested that the incidence of ROP is decreasing in developed nations. ${ }^{45} \mathrm{~A}$ study in Denmark found a decrease in the incidence in ROP for infants with birth weights between 1251 and $1750 \mathrm{~g}$ but not for infants weighing less than 1251 g. ${ }^{6}$ These smaller premature infants are more likely to suffer from ROP and the neurological sequelae of intraventricular haemorrhage and hypoxia. ${ }^{7}$ The Light-ROP study showed no reduction in incidence of ROP. ${ }^{8}$ At the present time in San Francisco, approximately $20 \%$ of children referred for preschool services to the Variety Club for Blind Babies Foundation have ROP. Increasingly, they are multiply handicapped with severe neurological and developmental problems. While it is true that improved neonatal care has resulted in an improved survival and quality of life for premature infants, ROP remains an important cause of childhood visual impairment in the developed world. Finally, although it is too little spoken of, the incidence of ROP in developed nations is significantly affected by the guidelines established by neonatal units for resuscitating and supporting very ill tiny premature babies. This is an ethical dilemma in which open discussion and debate would be welcomed.

In the Third World where no neonatal units are available, ROP is, of course, not a problem. However, as emerging nations develop neonatal care nurseries ROP becomes a larger part of the picture of childhood blindness. Establishing guidelines for screening and treating ROP are essential in these countries. The study of Kocur and co-workers identified 96 children with ROP. Yet, only four of these children had been treated with cryotherapy. Surely, this suggests that many of these children were cared for in neonatal units that did not have adequate screening or treatment programmes for ROP. The emphasis of the authors on establishing such programmes is well placed. Certainly, in some parts of the world this is a staffing issue with too few available ophthalmologists trained to screen for ROP. Of course, even with a well established programme of screening for ROP our treatment options remain limited and not entirely effective. ${ }^{9}$ ROP remains a problem for all but the poorest nations without neonatal intensive care units.

Conspicuous by its insignificance in the study of Kocur and co-workers is cortical visual impairment. They found only four children in their study with this diagnosis. This is striking and deserves comment. In the developed world ocular causes of visual impairment and blindness in children have decreased in frequency during the 20th century. In contrast, various central nervous system disorders have become the most common causes of visual impairment in children in many countries. ${ }^{10}{ }^{11}$ The term cortical visual impairment has been used to describe these central nervous system disorders. The original definition of cortical visual impairment was loss of vision due to bilateral dysfunction of the optic radiations and/or visual cortex. Recently, however, it has regrettably been applied to a myriad of disorders including autism, learning disabilities, and attention deficit disorders. For the purpose of this discussion we shall use cortical visual impairment to describe children with visual loss due to optic radiation, striate cortex, and peristriate cortex damage. Causes of cortical visual impairment in children include, but are not limited to, perinatal hypoxia, near drowning episodes, hydrocephalus, trauma (including non-accidental), meningitis, and periventricular leucomalacia. Many of these children have damage to non-visual portions of the central nervous system and are therefore significantly handicapped in functions other than vision. Many have severe neurodevelopmental problems and for this reason often are excluded from residential schools for the blind. Since Kocur and co-workers performed their study in 10 primary schools for visually handicapped children this may account at least in part for why they found only four children with the diagnosis of cortical visual impairment.

The child with cortical visual impairment is challenging to his/her parents, physicians, and teachers. Standard techniques to evaluate visual function are often inadequate to describe precisely the extent and nature of visual impairment. Educational approaches for intervention designed for the child with ocular causes of visual impairment are often unsuccessful. Recently, educators have developed specific instructional intervention strategies for the child with cortical visual impairment; nevertheless, the potential for the child with cortical visual impairment to live an independent and productive life is often not good.

In San Francisco, the two leading causes of childhood blindness and visual impairment are ROP and cortical visual impairment. In some ways they both result from

Reproduced with permission from the British fournal of Ophthalmology 2001;85:1145-6. 
improved medical care and technology which has allowed very premature and/or severely brain damaged children to survive. It is not altogether precise to refer to them as iatrogenic disorders but there are complex difficult ethical issues raised by these disorders which should remind us that advances in medical technologies are frequently accompanied by significant adverse effects. If our goal is to eliminate preventable causes of blindness by 2020, ROP and cortical visual impairment must be involved in a major portion of the effort on behalf of visually impaired children in the developed world.

CREIG S HOYT

University of California, Department of Ophthalmology,

10 Kirkham Street, K 301, San Francisco, CA 94143-0730, USA

choyt@itsa.ucsf.edu

WILLIAM V GOOD

Smith-Kettlewell Eye Research Institute, 2318 Filmore Street,

San Francisco, CA 94115, USA

Good@ski.org
1 World Health Organization. Preventing blindness in children. Report of a WHO/IAPB scientific meeting. WHO/PBL/00.77. Geneva: WHO, 2000.

2 Thylefors B. A global initiative for the elimination of avoidable blindness. Am f Ophthalmol 1998;125:90-3.

3 Gilbert CE, Rahi J, Eckstein M, et al. Retinopathy of prematurity in middleincome countries. Lancet 1997;350:12-14.

4 Bullard SR, Donahue SP, Feman SS, et al. The decreasing incidence and severity of retinopathy of prematurity. $\mathcal{F}$ AAPOS 1999;3:46-52.

5 Rowlands E, Ionides ACW, Chinn S, et al. Reduced incidence of retinopathy of prematurity. Br $\mathcal{F}$ Ophthalmol 2001;85:933-5.

6 Fledelius HC, Dahl H. Retinopathy of prematurity, a decrease in frequency and severity. Trends over 16 years in a Danish county. Acta Ophthalmol Scand 2000;78:359-66.

7 Volpe JJ. Intraventricular hemorrhage and brain injury in the premature infant. Neuropathology and pathogenesis. (Review) Clin Perinatol 1989;16: 361-386.

8 Reynolds JD, Hardy RJ, Kennedy K, et al. Light reduction in retinopathy of prematurity (Light-ROP) Cooperative group. Lack of efficacy in preventing retinopathy of prematurity. N Engl f Med 1998;328:1572-6.

9 Good WV, Gendron RL. Gene therapy for retinopathy of prematurity: the eye is a window to the future. Br F Ophthalmol 2001;85:908-11.

10 Rosenberg T, Flage T, Hansen E, et al. Incidence of registered visual impairment in the Nordic child population. Br f Ophthalmol 1996;80:49-53.

11 Huo R, Burden SK, Hoyt CS, et al. Chronic cortical visual impairment in children: aetiology, prognosis, and associated neurological deficits. $\mathrm{Br} \mathcal{F}$ Ophthalmol 1999;83:670-5.

\section{Applications are invited for the post of: Editor in chief}

\section{Archives of Disease in Childhood}

Speciolists in any bronch of poediatrics are invited to apply for the post of editor in chief. Plecse send a letter of opplication, a concise curriculum vitoe, your onclysis of the strengths and weoknesses of $A D C$ and a statement obout your proposed editorial policy.

Full editorial support and training will be provided. The editorial office is based in BMA House in landon and any necessary travel expenses will be reimbursed.

Closing date is 31st December 2001. Interviews will be held shortly thereatter to enable the successful candidate to take up the post mid 2002.

Defails of the post can be discussed with Dr Harvey Marcovitch, (hmarcovitchebmigroup.com) the current editor in chief or with Mrs Alex. Williomson. A job description is avoilable on request.

Applications should be sent to: Mrs Alex Williamson, BMU Publishing Group, BMA House, Tavistock Square, London WCIH 9JR Tel: +44 207383 6169; Fax; +44 207383 6668; email: awilliamsonebmigroup.com

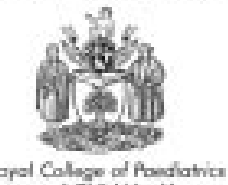

aed Chat Holt

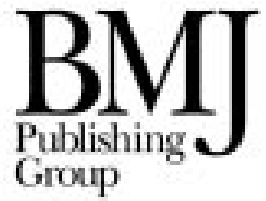




\section{CORRECTION}

We are sorry that the paper "Outcome for staged reconstructive surgery for hypoplastic left heart syndrome following antenatal diagnosis"1 was accompanied by an editorial ${ }^{2}$ based on outdated figures. Regrettably, we inadvertantly sent Dr Salmon the old version on which to base his article. Had he been sent the final version, he may have drawn more positive conclusions, as the results had improved over time. Unfortunately many readers may look at the editorial only, trusting that it provides an accurate summary, rather than the paper itself. Those who did take the trouble to read both articles side by side may have been confused by the apparent discrepancies.

We would like to take this opportunity to set the record straight, by providing updated versions of figures 1 and 2 from the paper. ${ }^{1}$ These illustrate the continued improvement in survival rates following staged palliative reconstructive surgery for this previously fatal condition. The updated figures show that stage I survival has increased from $52 \%$ to $59 \%$, and overall survival from $48 \%$ to $55 \%$. For antenatally diagnosed babies, survival has risen from $49 \%$ to $55 \%(39 / 71)$, or from $44 \%$ to $50 \%(39 / 78)$ taken from an "intention to treat" basis.

The management of HLHS remains a challenge, but we are encouraged that short to medium term results continue to improve over time. Although the highest mortality still occurs at stage I, the prospects for a baby entering the Norwood programme in 2001 are considerably better than those from even 5 years ago; stage I survival has risen from 54\% $(7 / 13)$ in 1996 to $87 \%(13 / 15)$ in 2001 $(\mathrm{p}=0.05)$. The authors conclude that it is crucial that parents are given accurate, up-todate figures when they are counselled about the outcome of this condition. ${ }^{3}$

The Editors

\section{References}

1 Andrews R, Tulloh R, Sharland G, et al. Outcome of stage reconstructive surgery for hypoplastic left heart syndrome following antenatal diagnosis. Arch Dis Child 2001;85:474-7.

2 Salmon AP. Hypoplastic left heart syndrome-outcome and management. Arch Dis Child 2001;85:450-1.

3 Sharland G, Rollings S, Simpson J, et al. Hypoplastic left heart syndrome [letter]. Lancet $2001 ; 357: 722$.

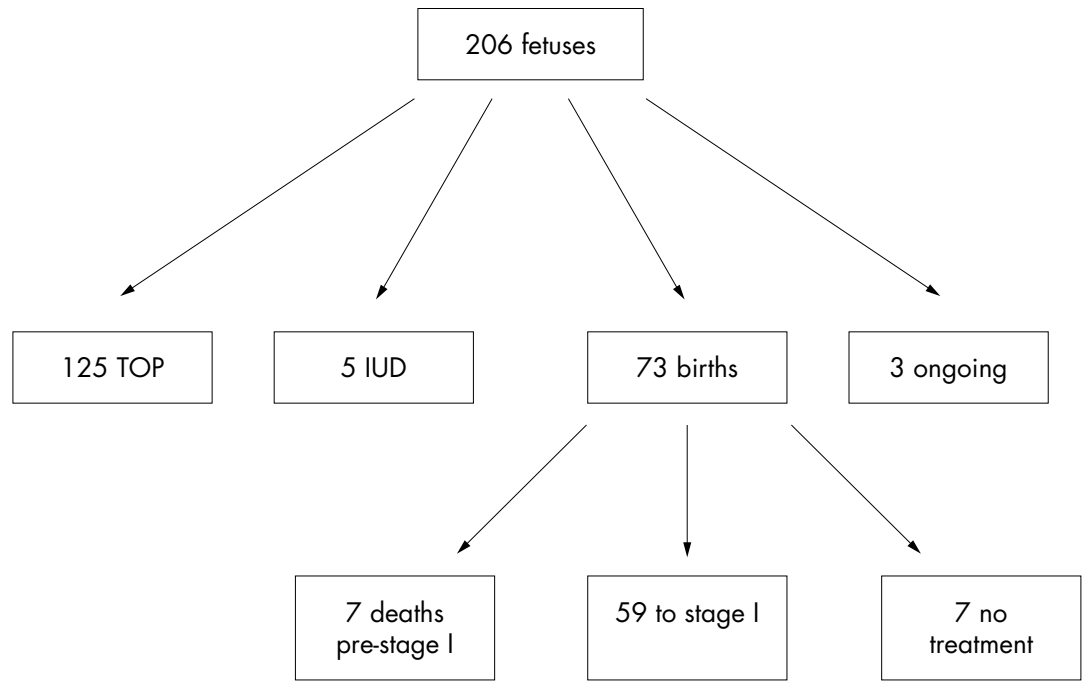

Figure 1 Outcome of 206 fetuses with HLHS diagnosed antenatally at Guy's Hospital between July 1995 and November 2001. TOP: termination of pregnancy; IUD: intrauterine death.

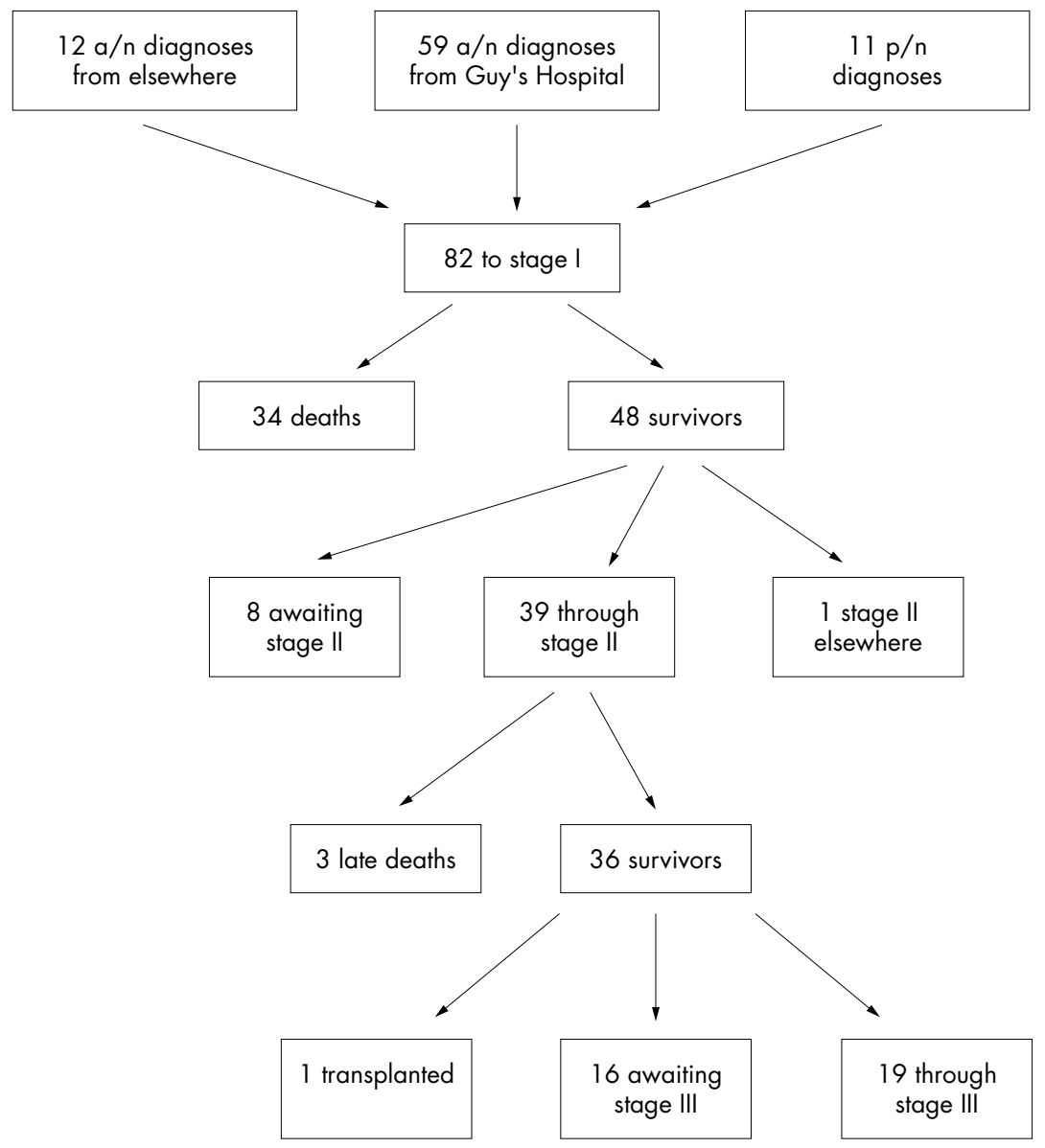

Figure 2 Outcome of 82 children with HLHS entered into the Norwood programme between July 1995 and November 2001. a/n: antenatal; p/n: postnatal. 